\title{
PREDICTION OF SPATIALLY DISTRIBUTED SEISMIC DEMANDS IN SPECIFIC STRUCTURES: GROUND MOTION AND STRUCTURAL RESPONSE
}

\author{
Brendon A Bradley ${ }^{*}$, Rajesh P Dhakal, Gregory A MacRae, Misko Cubrinovski \\ Department of Civil and Natural Resources Engineering, University of Canterbury, Private Bag 4800, \\ Christchurch 8020, New Zealand \\ *Corresponding author: $\mathrm{Ph}+64-3-3667001$ ext 7673; Fax: +64-3-364 2758; \\ Email: bab54@student.canterbury.ac.nz
}

\begin{abstract}
The efficacy of various ground motion intensity measures (IM's) in the prediction of spatially distributed seismic demands (Engineering Demand Parameters, EDP's) within a structure is investigated. This has direct implications to building-specific seismic loss estimation, where the seismic demand on different components is dependent on the location of the component in the structure. Several common intensity measures are investigated in terms of their ability to predict the spatially distributed demands in a 10-storey office building, which is measured in terms of maximum interstorey drift ratios and maximum floor accelerations. It is found that the ability of an IM to efficiently predict a specific EDP depends on the similarity between the frequency range of the ground motion which controls the IM and that of the EDP. An IM's predictability has a direct effect on the median response demands for ground motions scaled to a specified probability of exceedance from a ground motion hazard curve. All of the IM's investigated were found to be insufficient with respect to at least one of magnitude, source-to-site distance, or epsilon when predicting all peak interstorey drifts and peak floor accelerations in a 10-storey RC frame structure. Careful ground motion selection and/or seismic demand modification is therefore required to predict such spatially distributed demands without significant bias.
\end{abstract}

\section{KEYWORDS}

Spatially distributed seismic demand, predictability, efficiency, sufficiency, ground motion selection.

\section{INTRODUCTION}

The seismic response of structural systems is complex with ground motion shaking causing a response that varies significantly in space and time. This complex response can result in significantly different acceleration and displacement demands at spatially different locations in a structure, which will depend on its dynamic characteristics, as well as the properties of the ground motion record exciting the structure.

In emerging performance-based frameworks such as the Pacific Earthquake Engineering Research (PEER) Centre performance-based earthquake engineering (PBEE) methodology [1] uncertainties in all aspects (from ground motion to loss estimation) of the seismic analysis of structures can be explicitly incorporated and propagated to obtain performance measures useful for decision making. In such a probabilistic framework, there are transparent advantages in being able to reduce uncertainties in each of the aforementioned aspects, since uncertainties inevitably result in an increase in the risk of structural failure and/or economic losses for infrequent hazards such as those posed by seismic-induced ground shaking. 
An area of research in the past decade has been the investigation of ground motion intensity measures (IMs) which provide the link between the seismic hazard curve (which gives the probability/frequency of exceedance of a specific level of IM) and structural response (giving the distribution of the engineering demand parameter, EDP, for a given IM). An 'optimal' intensity measure must possess efficiency [2], sufficiency [3], predictability [4] and scaling robustness [5]. The aspects of efficiency and sufficiency have been studied in detail by Cornell and co-workers (e.g. [5-9]) where the seismic response of structures was measured simply via the maximum interstorey drift over all floors (which relates well to joint rotations in structural elements and therefore the potential for structural collapse). Predictability relates to the accuracy in predicting an IM from ground motion prediction equations. With the increased interest in ground motion selection methods (e.g. [10]), scaling robustness seeks to determine if the distribution of EDP using scaled ground motions is biased compared with that obtained using un-scaled ground motions [11]. Optimal intensity measures for total floor accelerations have received less attention than that of peak interstorey drifts, with the exception of Taghavi and Miranda [12] who examined the efficiency of four different IMs at predicting peak floor accelerations using simple elastic structural models.

The significant spatial variation in the response of structural systems with several or more storeys means that separate consideration must be given to each of these demands when rigorously considering the seismic performance of such systems within the PEER framework. As such, loss estimation methods used within the PEER PBEE framework typically employ a vector of EDPs which account for these spatially varying demands (typically maximum interstorey drift ratios and maximum floor accelerations). Furthermore, ground motion IMs which are efficient, sufficient, predictable and robust to scaling for this vector of EDP values are required.

Aslani [13] considered the efficiency and sufficiency of four different IMs for use in predicting spatially distributed demands in structures, and this research is intended to extend the work of Aslani [13] in the following ways: (1) seismic hazard curves for each of the ground motion IMs are developed independently allowing explicit consideration of the predictability of the different IMs; (2) consideration is given to efficiency, sufficiency, predictability, and scaling robustness of the IMs; (3) ground motion selection based on hazard deaggregation is employed; and (4) $50^{\text {th }}$ percentile rotation independent geometric mean (GMRotI50) intensity measures are used in both hazard computations and seismic response analysis.

The purpose of this paper is to use common IMs presented in literature, and for a specific structure investigate their predictability, efficiency, sufficiency, and scaling robustness in predicting peak interstorey drifts and total floor acceleration demands throughout the structure. In a companion paper [14], correction for IM insufficiency, as well as the resulting demand hazard, collapse hazard, and loss estimation results based on the different IMs is considered.

\section{STRUCTURE CONSIDERED}

The case study structure used herein is based on the geometry of the 'Red Book building' [15], a ten storey reinforced concrete (RC) structure, which acts as a design example of the New Zealand Concrete Code [16]. The primary lateral load carrying system consists of four one-way perimeter moment resisting frames which are 3 bays long. Vertical loads are transferred primarily through interior columns with gravity beams supporting one-way floor units.

A perimeter frame 2D model was developed using the finite element analysis program OpenSees [17]. Due to the symmetry of the structure, it was assumed that the 3D response 
could be reasonably approximated by separate $2 \mathrm{D}$ analyses in each of the two primary frame directions. The effects of foundation flexibility due to soil-foundation interaction were considered simply by using elastic rotational springs at the base of the columns [18]. The structure was modelled using a lumped mass model and non-linear (beam) elements with the appropriate backbone properties determined using fibre-based section modelling, and stiffness and strength degradation based on calibration with experimental tests [19]. The structural model had a fundamental period of $T_{1}=1.74$ seconds. Based on a pushover analysis it was determined that the 'yield' displacement, $d_{y}$, of the structure was $10 \mathrm{~cm}$ (this is used for the inelastic spectral displacement IM, $S_{d i}$ ).

The seismic demand due to ground motion excitation was monitored via peak interstorey drift ratios and peak floor accelerations at each floor in the structure (i.e. a total of ten drifts and eleven accelerations).

\section{GROUND MOTION INTENSITY MEASURES AND SEISMIC HAZARD}

In order to investigate the prediction of spatially distributed demands in structures a variety of ground motion IMs are selected. As there have been numerous ground motion IMs presented in the literature relating to various different aspects of structural behaviour it is necessary to apply some criteria to determine which IMs to investigate in this research. Firstly, it was desired to consider several IMs which have been used by other researchers when examining structural response from a probabilistic viewpoint. Secondly, and more importantly, all IMs used had to have a 'robust' ground motion prediction equation which can be used to develop seismic hazard curves using this IM at a variety of sites. This second point is particularly important as many studies have focused on the consideration of somewhat complex IMs which may be a combination of several 'standard' IMs in an effort to achieve better response prediction (i.e. efficiency). However, without a ground motion prediction equation for such an IM, no ground motion hazard curves can be developed, and hence no PBEE assessment can be performed using this IM. The term 'robust' has been used in order to differentiate between simple ground motion prediction equations based on limited data, and comprehensive ground motion prediction equations based on large ground motion databases which consider many features known to affect ground motion prediction (e.g. faulting types, hanging wall effects, local soil effects) such as those of the next generation attenuation (NGA) project [20].

Based on the above criteria a total of five different ground motion IMs were selected, namely: peak ground acceleration $(P G A)$; peak ground velocity $(P G V)$, elastic spectral displacement $\left(S_{d e}\right)$; inelastic spectral displacement $\left(S_{d i}\right)$; and spectrum intensity $(S I) . P G A$ and $S_{d e}$ can be predicted from (elastic) spectral acceleration prediction equations, some of which now also include coefficients for computing $P G V$ [20]. Prediction of $S_{d i}$, defined as the peak displacement of a bilinear single degree-of-freedom oscillator [21], is obtained by combining a ground motion prediction equation for $S_{d e}$ with a ground motion prediction for the ratio $S_{d i} / S_{d e}$ [21] (while the empirical equation for $S_{d i} / S_{d e}$ was determined using one specific ground motion prediction equation Tothong and Cornell [21] argue that it can be used with any prediction equation for $S_{d e}$ ). Finally, a ground motion prediction equation for $S I$, defined as the integral of the pseudo-spectral velocity from 0.1-2.5 seconds [22], can be computed directly from ground motion prediction equations for spectral acceleration [23]. The effect of epistemic uncertainties is beyond the scope of this study. However, it should be noted that as all ground motion IM's have 'robust' prediction equations, then the effect of epistemic uncertainty is expected to be of a similar magnitude for all the different IMs.

A simple hypothetical site with a $30-\mathrm{m}$ averaged shear wave velocity of $600 \mathrm{~m} / \mathrm{s}$ was considered as illustrated in Figure 1a, which is a closest distance of $15 \mathrm{~km}$ from a $40 \mathrm{~km}$ 
strike-slip fault. The fault has a Gutenberg-Richter magnitude distribution with $\alpha=3.0$ and $\beta=0.8$; minimum and maximum magnitudes of 5.0 and 7.5, respectively; and events assumed to be Poissonian in time. Based on this hypothetical scenario and using the Boore and Atkinson [24] ground motion prediction equation for $P G A, P G V$ and $S_{d e}$; the prediction equation of Tothong and Cornell [21] for $S_{d i}$; and the prediction equation of Bradley et al. [23] for $S I$ (with Boore and Atkinson [24] used as the 'base' prediction equation for both $S_{d i}$ and $S I)$, the ground motion hazard curves shown in Figures 1b-1d were determined using the probability-based formulation for the ground motion hazard [25]. Because of the initial period of the structure it is observed that the elastic and in-elastic spectral displacement hazards are similar in Figure 1c (i.e. the equal displacement rule). Note that the $50^{\text {th }}$ percentile orientation-independent geometric mean of the two horizontal ground motion components, GMRotI50 [26], definition for the ground motion intensity measures has been used in computing the hazard curves for all five IMs.

(a)

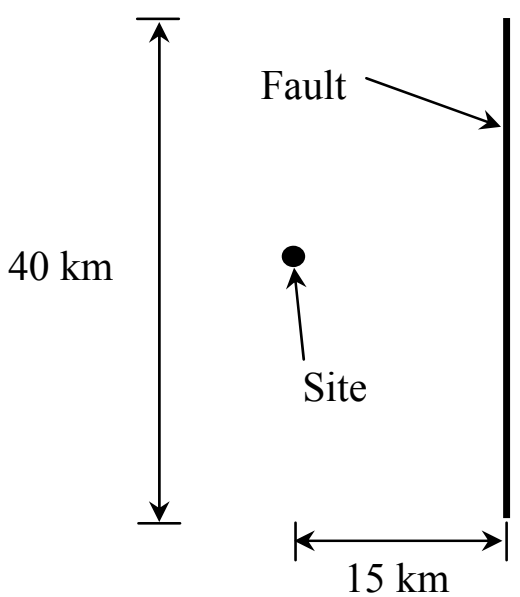

छ્ (c)

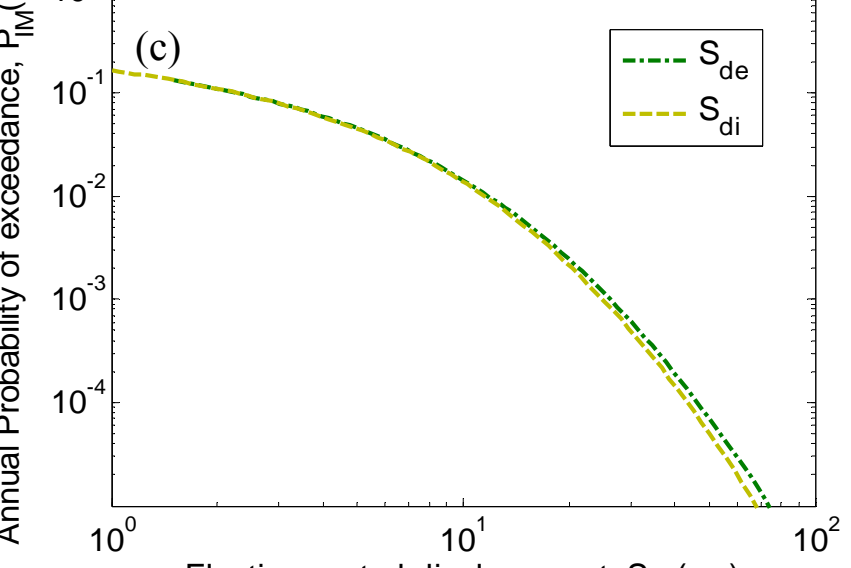

Elastic spectral displacement, $S_{\text {de }}(\mathrm{cm})$

Inelastic spectral displacement, $\mathrm{S}_{\mathrm{di}}(\mathrm{cm})$
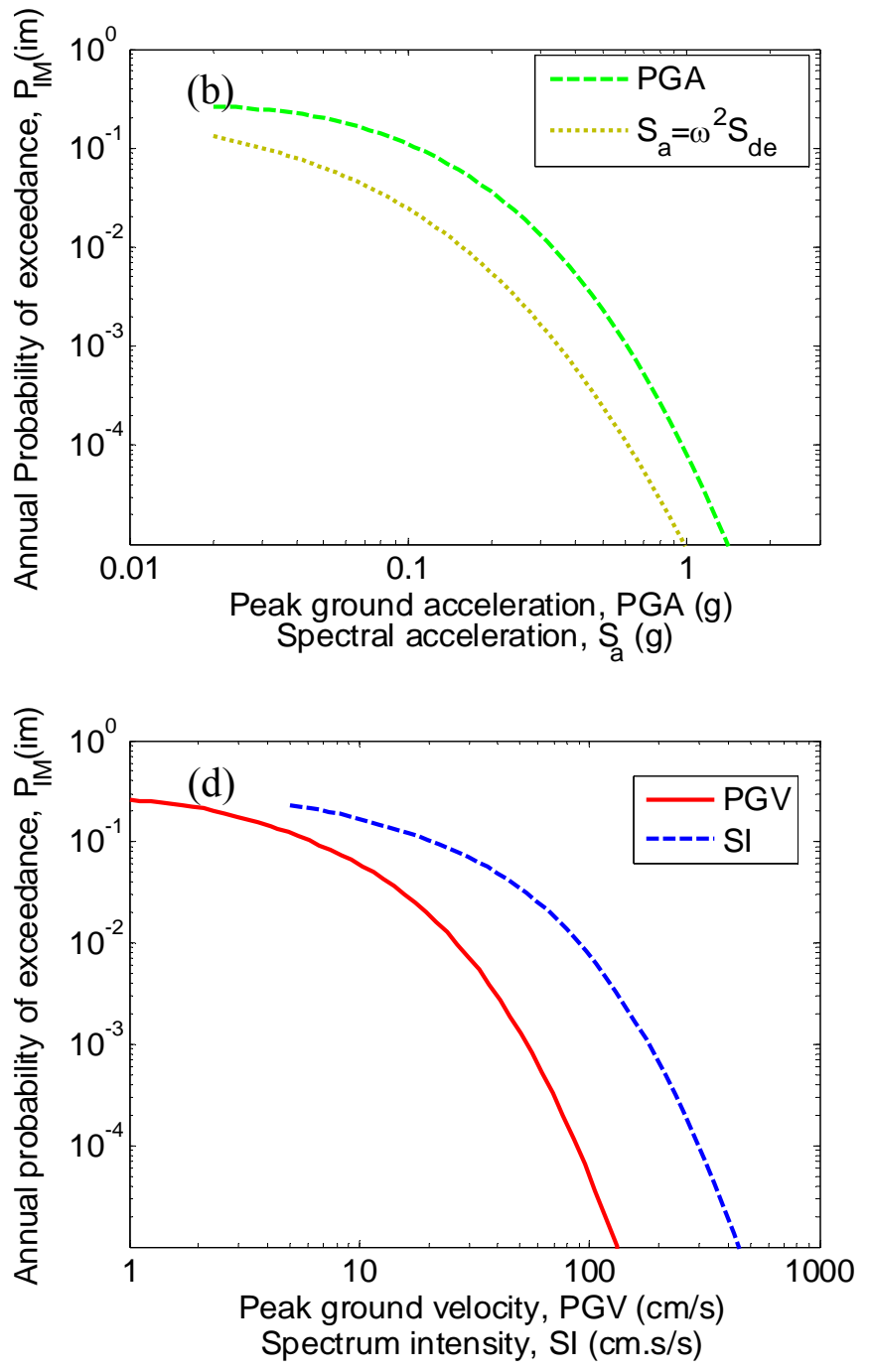

Figure 1: Hypothetical site considered and ground motion hazard curves for the five different ground motion intensity measures (IMs) considered.

\section{GROUND MOTION SELECTION}

It is important to carefully select ground motion records for use in dynamic analysis to avoid bias in structural response [27]. Ground motion records should be selected which are representative of those which are most likely to occur at the site of interest in the future. 
Hence, the target is to select a suite of ground motions which has the same distribution of ground motion properties as the deaggregation [28, 29] of the seismic hazard at the site. In the remainder of the manuscript particular attention will be given to the spatial distribution of seismic demands for ground motions which have exceedance probabilities of $1 / 475$ and $1 / 2475$ (corresponding to $10 \%$ and $2 \%$ probabilities of exceedance in 50 years, respectively). Table 1 gives the mean moment magnitude $\left(M_{w}\right)$, (Boore-Joyner) source-to-site distance $(R)$, and epsilon ( $\varepsilon$, defined as the number of standard deviations a specific ground motion parameter is above the predicted mean) for the five different IMs obtained by deaggregation of the seismic hazard at these exceedance probabilities. It can be seen that for a given IM, the mean $M_{w}$, and $\varepsilon$ are larger and mean $R$ smaller for the $1 / 2745$ exceedance probability compared to the $1 / 475$ exceedance probability. In addition, for a given exceedance probability it is observed that there are quite significant differences between the mean $M_{w}, R$ and $\varepsilon$ values for the different IMs, since they are affected by different properties of the ground motion. $M_{w}$ and $R$ obviously affect the intensity, frequency content and duration of ground motion records, and it has also been shown that when spectral ordinates are used as a ground motion IM (i.e. $P G A$ and $S_{d e}$ used in this study) that $\varepsilon$ has an effect on structural response, as it relates to spectral shape [6]. $S_{d i}$ has been shown to be (relatively) insensitive to $\varepsilon$ (when predicting the peak interstorey drift over all floors), since $S_{d i}$ directly accounts for spectral shape in the case of period elongation [5]. The effect of $\varepsilon$ on $P G V$ and SI has not been researched in detail.

Table 1: Statistics of the ground motion hazard deaggregation and suite of ground motion records used.

\begin{tabular}{|c|c|c|c|c|c|c|c|c|c|c|c|}
\hline & \multicolumn{4}{|c|}{$\mathrm{P}_{\mathrm{IM}}(\mathrm{im})=1 / 475$} & \multicolumn{3}{c|}{$\mathrm{P}_{\mathrm{IM}}(\mathrm{im})=1 / 2475$} & \multicolumn{3}{c|}{ Ground motion suite } \\
\hline & $\mathrm{IM}$ & $\mu_{M_{w}}$ & $\mu_{R}$ & $\mu_{\varepsilon}$ & $\mathrm{IM}$ & $\mu_{M_{w}}$ & $\mu_{R}$ & $\mu_{\varepsilon}$ & $\mu_{M_{w}}$ & $\mu_{R}$ & $\mu_{\varepsilon}$ \\
\hline$P G A(\mathrm{~g})$ & 0.515 & 6.93 & 18.8 & 1.58 & 0.744 & 7.01 & 18.5 & 2.14 & 6.49 & 20.8 & 1.17 \\
\hline$P G V(\mathrm{~cm} / \mathrm{s})$ & 44.1 & 7.16 & 18.8 & 1.26 & 66.2 & 7.24 & 18.5 & 1.88 & 6.49 & 20.8 & 1.58 \\
\hline$S_{d e}(\mathrm{~cm})$ & 20.9 & 7.04 & 18.9 & 1.46 & 33.4 & 7.10 & 18.7 & 2.06 & 6.49 & 20.8 & 1.57 \\
\hline$S_{d i}(\mathrm{~cm})$ & 20.1 & 7.03 & 19.0 & 1.44 & 31.6 & 7.10 & 18.8 & 2.08 & 6.49 & 20.8 & 1.57 \\
\hline$S I(\mathrm{~cm} . \mathrm{s} / \mathrm{s})$ & 148.3 & 7.11 & 18.7 & 1.34 & 223.3 & 7.17 & 18.3 & 1.89 & 6.49 & 20.8 & 1.76 \\
\hline
\end{tabular}

As the value of $\varepsilon$ depends on the IM and GMPE used and cannot currently be determined a priori (using, for example, the PEER NGA ground motion database [30]) then using the deaggregation results in Table 1, ground motions were initially selected based on wide range of $M_{w}, R$, and site $30-\mathrm{m}$ averaged shear-wave velocity $\left(V_{S_{30}}\right)$ (specifically $6.0<M_{w}$ $<8.0 ; 0<R<30 \mathrm{~km} ; 300<V s_{30}<800 \mathrm{~m} / \mathrm{s}$ ) giving a total of 155 ground motions (each with two orthogonal horizontal components). The $\varepsilon$ values for the five different ground motion parameters were determined and then the allowable ranges of $M_{w}, R, V s_{30}$, and $\varepsilon$ were further constrained to obtain a set of 25 ground motions (i.e. 50 different horizontal ground motion records for use in dynamic analysis) which were based on $6.2<M_{w}<7.7 ; 10<R<28 \mathrm{~km}$; $300<V s_{30}<800 \mathrm{~m} / \mathrm{s} ; \varepsilon$ (of any IM) $>0.4$. No constraints were placed on the number of recordings from a single event. The adopted ground motion records are presented in Table 2 and their statistics for the different IMs are summarised in Table 1. Note that the process for selecting ground motion records was conducted in an iterative fashion as it was not possible to find a large enough suite of records which match the statistics (mean and standard deviation) of the seismic hazard deaggregation exactly. Therefore a trade-off was required to try and match all $M_{w}, R$, and $\varepsilon$ values relatively well. 


\section{PREDICTION OF STRUCTURAL RESPONSE: DETERMINISTIC HAZARD SCENARIO}

Before investigating the efficacy of the five different ground motion IMs in predicting the spatially varying structural response for the $1 / 475$ and $1 / 2475$ probability of exceedance hazard levels, it is first necessary to test for any bias when comparing the different ground motion IMs. Potential sources of bias could be whether the selected ground motion record suite is equally representative for all five different ground motion IMs or whether the different ground motion prediction equations used to determine the scale factors (used to scale the amplitude of motion only) for each ground motion are consistent. To investigate the above points a deterministic earthquake scenario is considered with a moment magnitude of $M_{w}=7.0$ and a source-to-site distance of $R=18 \mathrm{~km}$. Note that this deterministic scenario is intentionally similar to the mean magnitude and distance obtained from deaggregation of the seismic hazard in Table 1. Table 3 gives the median and dispersion (lognormal standard deviation) for the ground motion IMs obtained from the ground motion prediction equations for the deterministic scenario. Figures $2 \mathrm{a}$ and $2 \mathrm{~b}$ illustrate the median (specifically, the mean of the logarithms which is the median assuming a lognormal distribution) and dispersion for the GMRotI50 acceleration response spectra obtained by scaling the ground motion records to the median IM for the deterministic scenario. Since the median response spectra of the 25 ground motion records scaled based on the five different IMs are very similar, it indicates that the selected ground motion suite and the different ground motion prediction equations do not introduce any significant bias when comparing the results of the structural analyses to follow. Note that this result was to be expected since all of the IMs use (or are derived from) the Boore and Atkinson [24] ground motion prediction equation and ground motions were selected to match hazard deaggregation. Figure $2 \mathrm{~b}$ provides insight into the effect of IM scaling on the dispersion in response spectra amplitudes as a function of vibration period. Obviously, $P G A$ scales all the ground motions to have the same spectral acceleration at $T=0$ so the dispersion is zero at $T=0$, and similarly for $S_{d e}$ at $T=T_{1}$. Also since the inelastic spectral displacement for this scenario, $S_{d i}=6.09 \mathrm{~cm}$, is less than the yield displacement of the inelastic single-degree-of-freedom (SDOF), $d_{y}=10 \mathrm{~cm}$, then the dispersion is also zero at $T=T_{1}$ for ground motions scaled to $S_{d i}$ (i.e. the $S_{d e}$ and $S_{d i}$ lines in Figure $2 \mathrm{~b}$ are coincident). An increase in response spectra dispersion with period is observed for ground motions scaled based on $P G A$, while in a similar fashion the dispersion increases as $T$ moves away from $T_{1}$ for $S_{d e}$ - and $S_{d i}$-based scaling. While scaling based on $P G V$ or $S I$ does not 'fix' the dispersion to zero at any point of the response spectra it is observed that apart from the small period window around $T=T_{1}$ (approximately $1.0<T<2.5$ ) the dispersion for both $P G V$ and $S I$ is lower than when ground motions are scaled to $S_{d e}$.

Figures $3 \mathrm{a}$ and $3 \mathrm{~b}$ illustrate the median response (in terms of maximum interstorey drift ratios and maximum floor accelerations) of the case study structure based on ground motion scaling using the five different IMs. As expected, the median response, both for interstorey drifts and floor accelerations are approximately the same for all five IMs. The minor exception being that ground motions scaled using $P G A$ give slightly larger interstorey drifts and floor accelerations over the lower portion of the structure. This is consistent with the slightly larger median response spectra over $1.0<T<3.0 \mathrm{~s}$ using $P G A$-scaling in Figure 2a. Figure $3 \mathrm{c}$ illustrates the dispersion in the maximum interstorey drifts for the deterministic scenario. It can be seen that over the lower half of the structure where the peak responses are primarily due to the first mode of vibration, that $S_{d e}$ (and $S_{d i}$ ) are the most efficient in predicting the interstorey drifts, while $P G A$ is the worst, and $S I$ is marginally better than $P G V$ as it contains spectral velocity information at periods around that of the first mode. In the upper-half of the structure, where the effects of higher vibration modes are more significant it is clearly seen that the efficiency of the spectral displacement IMs $\left(S_{d e}\right.$ and $\left.S_{d i}\right)$ reduces and the efficiency of 
$P G A$ increases. Figure $3 \mathrm{~d}$ illustrates the dispersion in the peak floor accelerations for the deterministic scenario. It is apparent that $P G A$ has the best efficiency for all floors, although the difference is less pronounced in the upper floors (where the structures dynamic characteristics have significantly modified the ground motion input at the base). On the other hand, spectral displacement IMs $\left(S_{d e}\right.$ and $\left.S_{d i}\right)$ are the worst at predicting the maximum floor accelerations over all floors. Note that the dispersion in the ground floor peak acceleration when using $P G A$ is not zero as the ground motion IMs are based on GMRotI50 [26] (i.e. the geometric mean of the two components), while only a single component is applied in each of the structural analyses. It is necessary to use the GMRotI50 definition for the IMs to be consistent with the ground motion hazard curves [31].

Table 2: Properties of the ground motions adopted

\begin{tabular}{|c|c|c|c|c|c|c|}
\hline ID $^{*}$ & Earthquake & Year & Recording station & $\mathrm{M}_{\mathrm{W}}$ & $\mathrm{R}(\mathrm{km})$ & $\begin{array}{c}\mathrm{Vs}_{30} \\
(\mathrm{~m} / \mathrm{s})\end{array}$ \\
\hline 125 & Friuli, Italy & 1976 & Tolmezzo & 6.50 & 14.97 & 425 \\
\hline 265 & Victoria, Mexico & 1980 & Cerro Prieto & 6.33 & 13.80 & 660 \\
\hline 339 & Coalinga & 1983 & Parkfield - Fault Zone 15 & 6.36 & 28.00 & 376 \\
\hline 359 & Coalinga & 1983 & Parkfield - Vineyard Cany 1E & 6.36 & 24.83 & 339 \\
\hline 369 & Coalinga & 1983 & Slack Canyon & 6.36 & 25.98 & 685 \\
\hline 587 & New Zealand & 1987 & Matahina Dam & 6.60 & 16.09 & 425 \\
\hline 755 & Loma Prieta & 1989 & Coyote Lake Dam (SW Abut) & 6.93 & 19.97 & 598 \\
\hline 776 & Loma Prieta & 1989 & Hollister - South \& Pine & 6.93 & 27.67 & 371 \\
\hline 952 & Northridge & 1994 & Beverly Hills - 12520 Mulhol & 6.69 & 12.39 & 546 \\
\hline 963 & Northridge & 1994 & Castaic - Old Ridge Route & 6.69 & 20.10 & 450 \\
\hline 995 & Northridge & 1994 & LA - Hollywood Stor FF & 6.69 & 19.73 & 316 \\
\hline 1003 & Northridge & 1994 & LA - Saturn St & 6.69 & 21.17 & 309 \\
\hline 1010 & Northridge & 1994 & LA - Wadsworth VA Hospital South & 6.69 & 14.55 & 414 \\
\hline 1077 & Northridge & 1994 & Santa Monica City Hall & 6.69 & 17.28 & 336 \\
\hline 1485 & Chi-Chi, Taiwan & 1999 & TCU045 & 7.62 & 26.00 & 705 \\
\hline 2461 & Chi-Chi, Taiwan & 1999 & CHY028 & 6.20 & 23.44 & 543 \\
\hline 2495 & Chi-Chi, Taiwan & 1999 & CHY080 & 6.20 & 21.34 & 553 \\
\hline 2618 & Chi-Chi, Taiwan & 1999 & TCU065 & 6.20 & 25.17 & 306 \\
\hline 2619 & Chi-Chi, Taiwan & 1999 & TCU067 & 6.20 & 27.66 & 434 \\
\hline 2626 & Chi-Chi, Taiwan & 1999 & TCU075 & 6.20 & 18.47 & 573 \\
\hline 2627 & Chi-Chi, Taiwan & 1999 & TCU076 & 6.20 & 13.04 & 615 \\
\hline 2655 & Chi-Chi, Taiwan & 1999 & TCU122 & 6.20 & 18.10 & 475 \\
\hline 2661 & Chi-Chi, Taiwan & 1999 & TCU138 & 6.20 & 21.11 & 653 \\
\hline 3300 & Chi-Chi, Taiwan & 1999 & CHY074 & 6.30 & 22.57 & 553 \\
\hline 3507 & Chi-Chi, Taiwan & 1999 & TCU129 & 664 \\
\hline
\end{tabular}

*ID as given on the NGA database. http://peer.berkeley.edu/nga/earthquakes.html 
Table 3: Median and dispersion in the ground motion IMs for the deterministic $\mathrm{M}_{\mathrm{w}}=7.0$, $\mathrm{R}=18 \mathrm{~km}$ scenario.

\begin{tabular}{|c|c|c|}
\hline $\mathrm{IM}$ & Median, $\exp \left(\mu_{\operatorname{lnIM}}\right)$ & Dispersion, $\sigma_{\ln I \mathrm{M}}$ \\
\hline$P G A(\mathrm{~g})$ & 0.187 & 0.564 \\
\hline$P G V(\mathrm{~cm} / \mathrm{s})$ & 15.78 & 0.560 \\
\hline$S_{d e}(\mathrm{~cm})$ & 6.19 & 0.690 \\
\hline$S_{d i}(\mathrm{~cm})$ & 6.09 & 0.672 \\
\hline$S I(\mathrm{~cm} . \mathrm{s} / \mathrm{s})$ & 52.4 & 0.592 \\
\hline
\end{tabular}
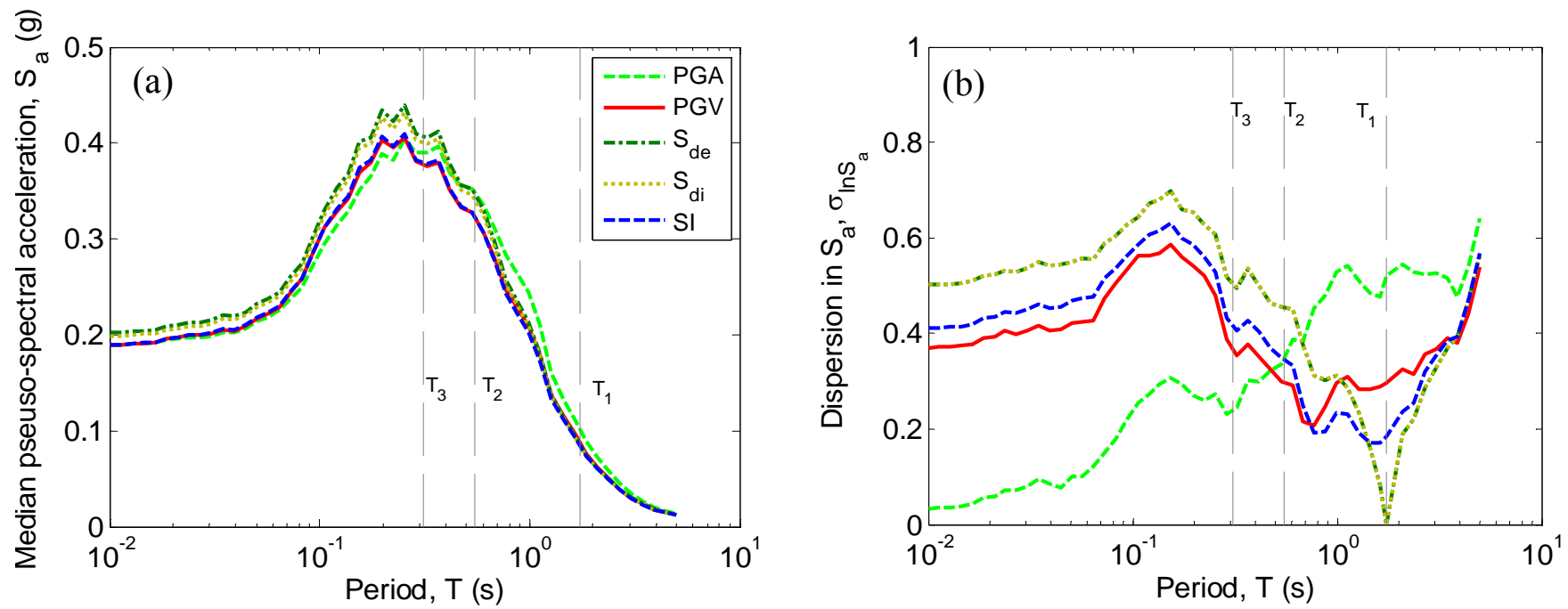

Figure 2: Response spectra of the ground motion suites scaled based on the different IMs for a $M_{w}=7, R=18 \mathrm{~km}$ scenario

The results of Figures $3 \mathrm{c}$ and $3 \mathrm{~d}$ are consistent with the results obtained by Aslani [13] and Taghavi and Miranda [12], and clearly indicate that the ability of various ground motion IMs to predict structural response EDPs depends on the similarity of the frequency range of the motion which dominates the EDP and that of the IM. For example, peak accelerations are dominated by high frequency content so $P G A$ is the most efficient IM, while displacements are dominated by lower frequency content so IMs in the lower frequency region (i.e. $S_{d e}$ and $S_{d i}$ in this case) are more efficient in displacement prediction. The velocity IMs ( $P G V$ and $\left.S I\right)$ being in the 'medium' frequency range (i.e. between accelerations and displacements) provide 'moderate' efficiency in predicting both maximum interstorey drifts and maximum floor accelerations.

\section{PREDICTION OF STRUCTURAL RESPONSE: PROBABILISTIC HAZARD}

The nature of the deterministic scenario presented in the previous section allowed Figures $3 c$ and $3 d$ to be viewed solely to investigate the efficiency of the five different IMs (in this case for a relatively small level of ground motion shaking). As mentioned previously however, the determination of an optimal IM contains several other criteria, one of which is the predictability of the IM. Predictability relates to the magnitude of the aleatory uncertainty in the ground motion prediction equation used to compute the ground motion hazard for a specific site. Predictability is an important property of a ground motion IM since it will affect the probability of a specific level of ground motion occurring. Bommer and Abrahamson [32, 
Figure 3] illustrate that the effect of a large uncertainty in a ground motion prediction equation (i.e. poor predictability) is to increase the likelihood of a specific level of ground motion intensity occurring, with the increase in likelihood becoming more significant at long return periods. As a direct indication of the predictability of the five different IMs considered here, Table 3 indicates the dispersion in the ground motion prediction equations for the deterministic scenario considered in the previous section. As is typical, the standard deviation of a response spectral ground motion prediction equation increases with response spectral period, as long period motion is more deterministically related to the earthquake source [33, p101] than short period motion (i.e. the predictability of $S_{d e}$ and $S_{d i}$ is worse than $P G A$ ), while the predictability of $P G A, P G V$ and SI are similar.
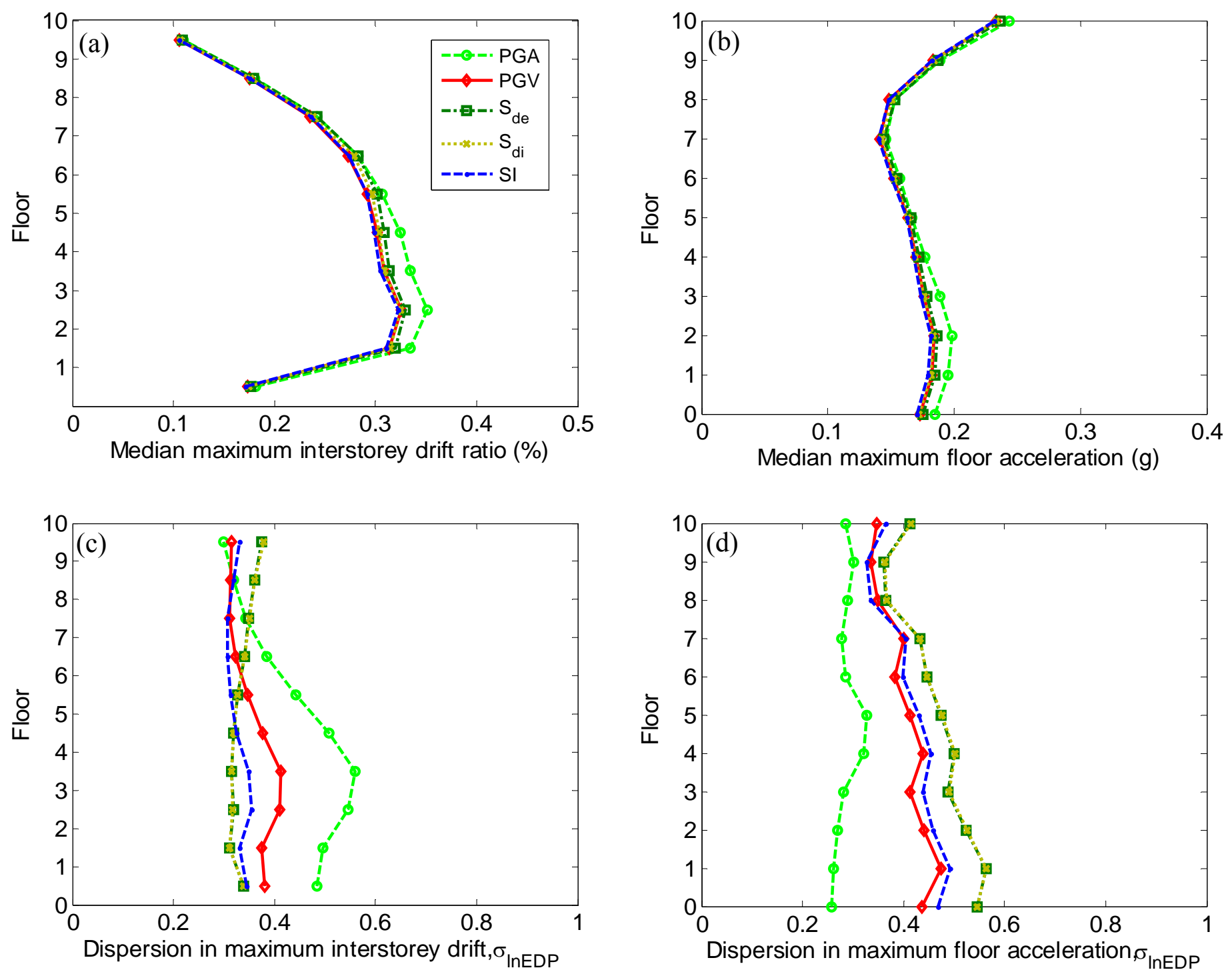

Figure 3: Median and dispersion in maximum interstorey drift and maximum floor acceleration demands for the various IMs for the deterministic scenario

\section{Interstorey drift response}

To illustrate the effects of predictability on the results of structural response analyses the ground motion records given in Table 2 were scaled to ground motion intensities which had $1 / 475$ and 1/2475 exceedance probabilities (using the hazard curves in Figure 1), the values 
for which are given in Table 1. Figure 4 illustrates the median and dispersion in the maximum interstorey drifts predicted using the various IMs for the two different exceedance probabilities. Unlike the deterministic scenario where all of the five IMs produced similar median demands, it is clear from Figures $4 \mathrm{a}$ and $4 \mathrm{~b}$ that there is a significant difference when the ground motions are scaled to the same exceedance probabilities. For example, scaling ground motions to $S I$ gives median values for the maximum interstorey drift between the $2^{\text {nd }}$ and $3^{\text {rd }}$ floors of $0.9 \%$ and $1.25 \%$ at the two different exceedance probabilities compared to $1.1 \%$ and $1.6 \%$ using ground motions scaled to $S_{d e}$ (i.e. $22 \%$ and $28 \%$ differences, respectively). It should be clear that the relative magnitude of the median values of the maximum interstorey drifts between the different IMs is closely related to the predictability of the different IMs.
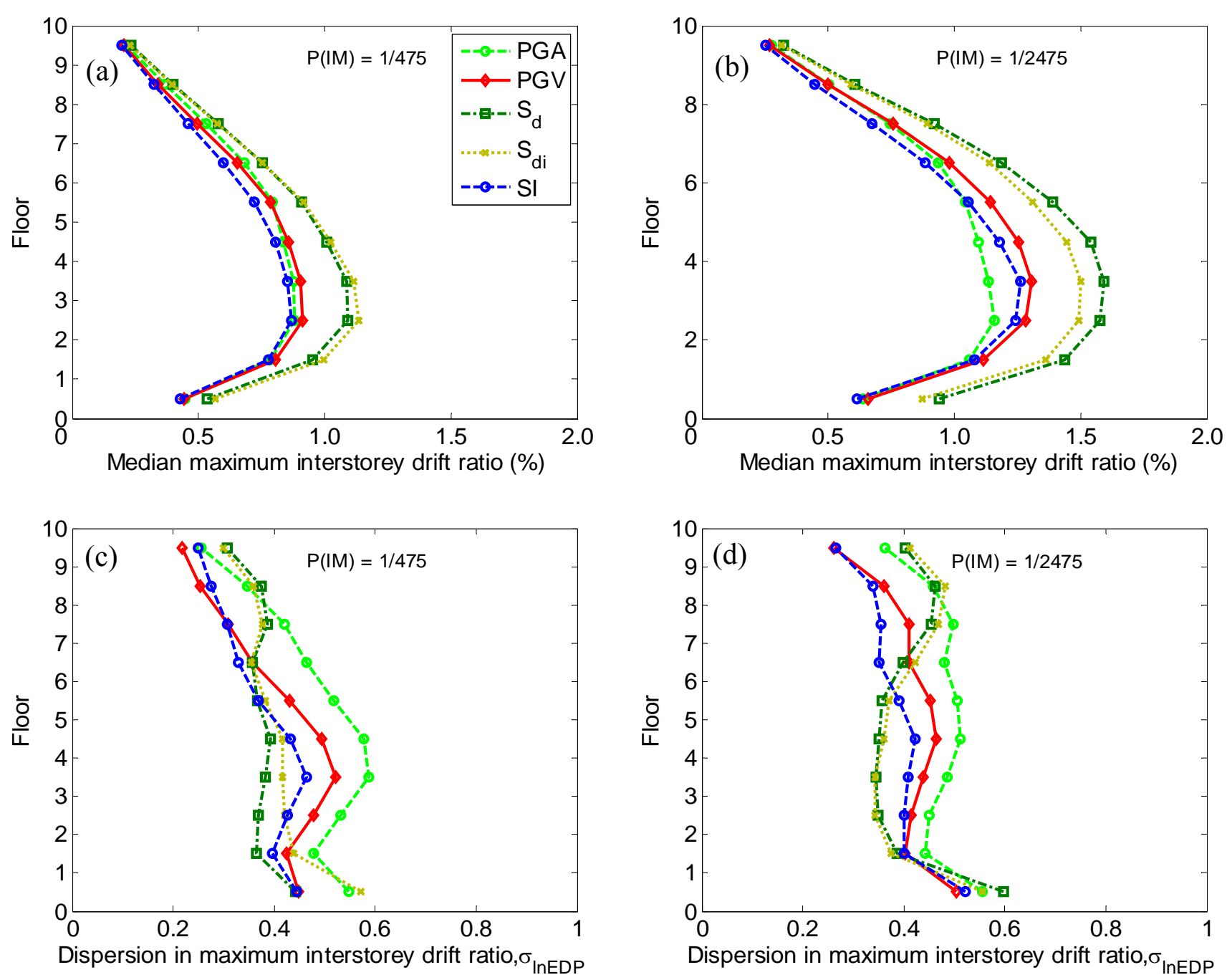

Figure4: Median and dispersion in the maximum interstorey drifts for ground motions scaled to the 1/475 and $1 / 2475$ exceedance probabilities using the various IMs.

Figures $4 \mathrm{c}$ and $4 \mathrm{~d}$ illustrate the dispersion in the maximum interstorey drifts obtained using the five different IMs for the $1 / 475$ and 1/2475 exceedance probabilities. The trends regarding efficiency in predicting maximum interstorey drifts are similar to those for the deterministic scenario with the key difference being that as the intensity of the ground motion increases inelastic response causes changes in the vibration characteristics of the structure. These changing vibration characteristics subsequently affect the efficiency in predicting the 
EDPs at different locations in the structure. For example, comparing the dispersion in the interstorey drifts at the $1 / 475$ and 1/2475 exceedance probabilities illustrates that increasing inelastic behaviour reduces the dispersion in the prediction of the interstorey drifts in the lower half of the structure and increases the dispersion in the upper floors.

\section{Floor acceleration response}

Figures $5 \mathrm{a}$ and $5 \mathrm{~b}$ illustrate the median values of the maximum floor accelerations for the various IMs. Similar to the median values of the interstorey drifts, it is observed that the relative magnitude of the maximum floor accelerations is directly related to the predictability of the IMs. A comparison of Figures $3 b, 5 a$ and $5 b$ illustrates the change in the spatial distribution of the peak floor accelerations as the ground motion intensity increases. For the aforementioned deterministic scenario the largest floor accelerations occur at the top of the structure due to the presence of significant higher mode effects. However as the ground motion intensity increases, inelastic behaviour in the lower floors of the structure (which causes an elongation in the effective period of the structure) effectively acts as a filter on the high frequency components of the ground motion. The same logic also explains why the maximum interstorey drift demands in the upper floors of the structure reduce (relative to the maximum interstorey drifts in the lower floors) as the ground motion intensity increases. Figures $5 \mathrm{c}$ and $5 \mathrm{~d}$ illustrate the dispersion in the prediction of the maximum floor accelerations at the $1 / 475$ and 1/2475 exceedance probabilities. Similar trends are observed compared to the deterministic scenario with $P G A$ being the most efficient IM and spectral displacements the worst. However, due to significant inelastic behaviour at the $1 / 2475$ exceedance probability, it is seen that the efficiency of $P G A$ in predicting peak accelerations on some floors is reduced.

It is interesting to observe in Figures 4 and 5 that there is little difference between the predictive capacity of $S_{d i}$ and $S_{d e}$ for the structure considered. Comparison with the results of Tothong and Luco [5, Table 2] however illustrates that $S_{d i}$ provides little improvement over using $S_{d e}$ for structures with fundamental period above 1.5 seconds. Also as careful ground motion selection has been used with respect to $\varepsilon$, then the results presented here for $S_{d e}$ are equivalent to somewhere between $S_{d e}$ and $S_{d e} \& \varepsilon$ presented in Tothong and Luco [5, Table 2]. In such cases an intensity measure, $I M_{1 I \& 2 E}$, which combines information of the inelastic first mode response and elastic higher modes can give better approximations of drift demands [5]. However, as $I M_{1 I \& 2 E}$ combines different mode contributions in terms of spectral displacements, then those spectral displacements due to higher modes are relatively small and it is not likely that $I M_{1 I \& 2 E}$ will be efficient in predicting floor acceleration demands. IM $M_{1 I \& 2 E}$ was not considered here as an IM since current ground motion prediction equations for $I M_{1 I \& 2 E}$ require the use of a first-order Taylor-series expansion (which is known to be inaccurate for the large uncertainty in ground motion prediction equations), and the 'equal displacement' assumption [34]. 

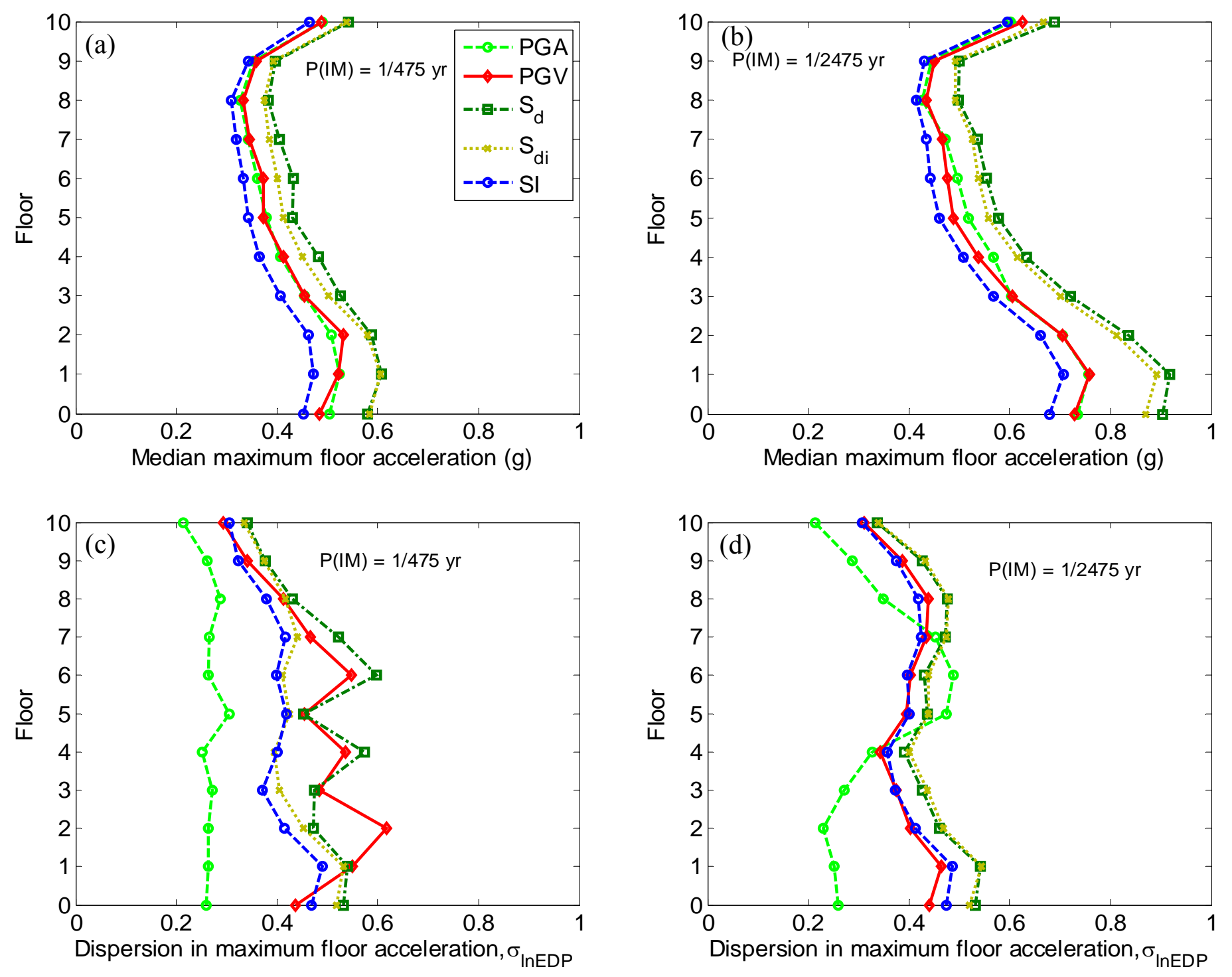

Figure 5: Median and dispersion in the maximum floor accelerations for ground motions scaled to the 1/475 and 1/2475 exceedance probabilities using the various IMs.

Figures $4 \mathrm{a}, 4 \mathrm{~b}, 5 \mathrm{a}$ and $5 \mathrm{~b}$ have illustrated that for a given exceedance probability, a significant reduction in the median response (specifically for this structure), both interstorey drifts and floor accelerations, can be obtained by using a predictable intensity measure such as $P G A, P G V$, and $S I$. This has a direct implication for current code-based applications for timehistory analysis which require that the average response be used for design if seven or more ground motion records are used [34]. Note that design codes state that the 'average' of the structural responses from the different ground motions should be used, where it is assumed that 'average' refers to the arithmetic mean of the responses (and not the mean of the logarithms of the responses used here to get the 'median'). Since for a lognormal distribution the ratio of the mean to the median is $\exp \left(\sigma_{\ln X}^{2} / 2\right)$, where $\sigma_{\ln X}$ is the dispersion, then it was found that $P G A, P G V$ and $S I$ give lower 'mean' responses than spectral displacements, $S_{d e}$ and $S_{d i}$.

\section{Conditional distribution of seismic demand given intensity measure}

In order to proceed from seismic response analysis results and compute demand hazard 
and loss estimation it is necessary to know the conditional distribution of the demand (EDP) given ground motion intensity (IM), i.e. $f(\mathrm{EDP} \mid \mathrm{IM})$. Due to the numerous permutations of the 21 different EDPs, five IMs and two different hazard levels considered, no attempt is made here to rigorously illustrate the observed distribution although it is pertinent to discuss such a topic. Reference is given to the numerous studies which have found that interstorey drifts [e.g., 2, 35] and floor accelerations [e.g., 35] are lognormally distributed. Note that Taghavi and Miranda [12] argue that peak floor accelerations are normally distributed, however their comparisons between empirical and analytic distributions were for ground motion IMs with dispersions which were less than 0.3 (in which case the normal and lognormal distributions are similar). Although not explicitly illustrated here, it was found that the conditional demand distribution, $f(\mathrm{EDP} \mid \mathrm{IM})$ was satisfactorily estimated using the lognormal distribution based on the Kolmogorov-Smirnov goodness-of-fit test [36] at a 5\% significance level (i.e. $\alpha=0.05$ ) for all of the EDP|IM permutations (which as shown in Figures 3-5 included dispersions from 0.25-0.75).

\section{SUFFICIENCY OF INTENSITY MEASURES}

The previous two sections have focused on the efficiency and predictability of an IM for estimating the spatially distributed demands in structures. The remaining property of an optimal IM is sufficiency; scaling robustness [5] can be thought of as sufficiency with respect to scale factor. Sufficiency (in this context) relates to the conditional independence of the distribution of EDP given IM on other parameters such as earthquake magnitude $\left(M_{w}\right)$, source-to-site distance $(R)$, and epsilon $(\varepsilon)$. IM sufficiency is important since the distribution, $f(E D P \mid I M)$ is obtained from the results of a finite number of seismic response analyses. Thus if the distribution $f(E D P \mid I M)$ is dependent on the $M_{w}, R$ and $\varepsilon$ values of the ground motions used, then the distribution will be biased if the distribution of $M_{w}, R$ and $\varepsilon$ of the ground motion records used in the seismic response analysis is not the same as that of the ground motions which will occur at the site in the future. Thus, mathematically speaking, sufficiency requires that $f(E D P \mid I M) \cong f\left(E D P \mid I M, M_{w}, R, \varepsilon\right)$, where the 'approximately equals' sign is intended to mean 'practically equal to'. In order to test for sufficiency linear regression is typically performed between some property of the ground motion records (i.e. $\left.M_{w}, R, \varepsilon\right)$ and the observed EDPs from the seismic response analysis [3]. Thus the coefficient $b$ from the linear regression line $E[\ln E D P]=a+b x$ (where $x$ is one of $M_{w}, R, \varepsilon$ ) indicates the dependence of the observed EDP values on the parameter $x$. Since the linear regression is based on a finite number of observations it is necessary to use statistical tests to determine the significance of the coefficient $b$. As an underlying assumption of linear regression is that the observations, lnEDP, are normally distributed, and since there are a finite number of observations, it follows that the coefficient, $b$ has a student-t distribution and the F-test can be used to determine the statistical significance of $b$ [36]. The F-test gives a 'p-value' which is the probability of the coefficient $b$ having a value at least as large as that observed, given that its underlying true value is zero. Typically p-values less than 0.05 are used to indicate a statistically significant value. For example, Figure 6a illustrates the sufficiency of $P G V$ with respect to source-to-site distance, $R$, for the peak interstorey drift between the $2^{\text {nd }}$ and $3^{\text {rd }}$ floors, while Figure $6 \mathrm{~b}$ illustrates the sufficiency of $S_{d e}$ with respect to epsilon for the peak $2^{\text {nd }}$ floor acceleration (both for the 1/475 exceedance probability). Figure 6a indicates that based on the finite observations the positive correlation between $\operatorname{lnEDP}$ and $R$ is statistically insignificant ( $\mathrm{p}$-value $=0.12>0.05)$, while the negative correlation between $\operatorname{lnEDP}$ and $\varepsilon$ in Figure $6 \mathrm{~b}$ is statistically significant $\left(\mathrm{p}\right.$-value $\left.=2.4 \times 10^{-6}<<0.05\right)$. Because of the numerous permutations for the five different IMs over the 21 different EDPs monitored in the case study 
structure, discussion in the remainder of the section is given with respect to p-values directly.
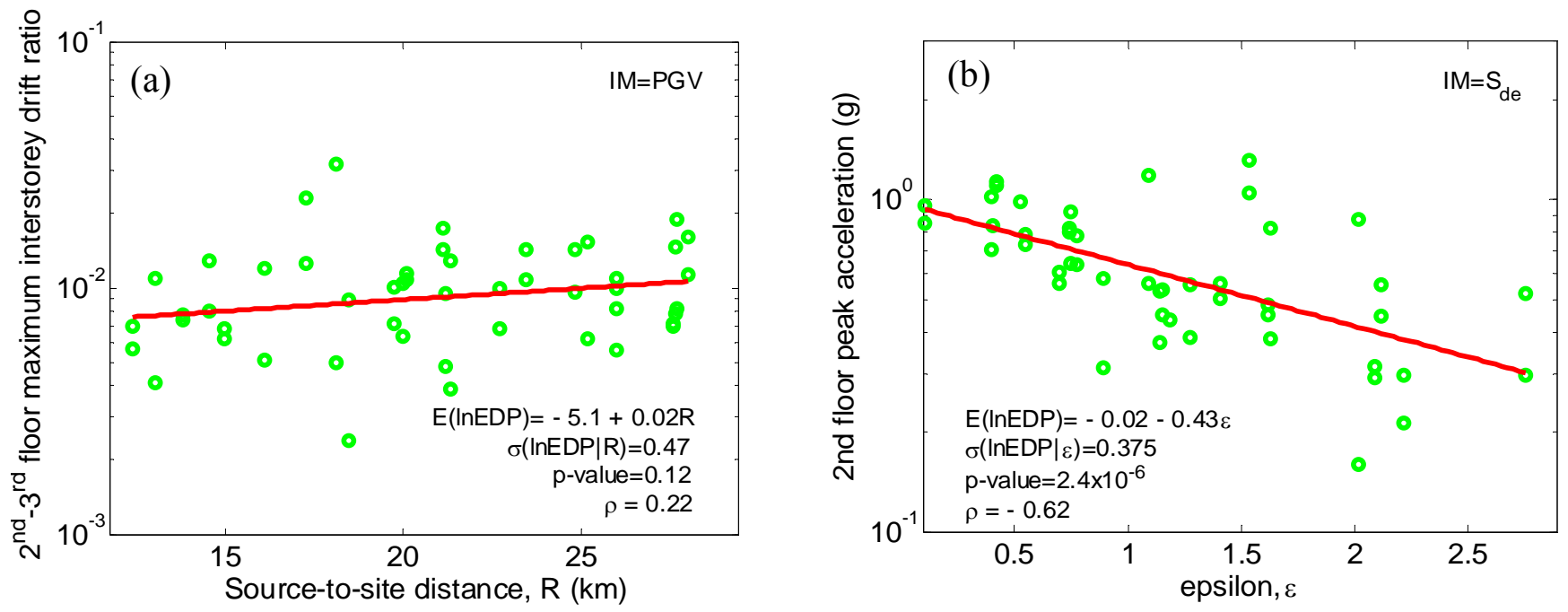

Figure 6: Sufficiency of: (a) peak ground velocity $(P G V)$ with respect to source-to-site distance in predicting the peak interstorey drift ratio between the $2^{\text {nd }}$ and $3^{\text {rd }}$ floors; and (b) spectral displacement $\left(S_{d e}\right)$ with respect epsilon in predicting the $2^{\text {nd }}$ floor peak acceleration.

\section{Sufficiency with respect to magnitude and source-to-site distance}

Several of the ground motion IMs used here have been investigated (regarding $M_{w}$ and $R$ sufficiency) previously for the peak interstorey drift and floor accelerations over all floors and are briefly reviewed here. Aslani [13] showed that for a seven-storey non-ductile frame structure $S_{d e}$ is sufficient with respect to $M_{w}$ and $R$ when used for predicting the maximum interstorey drift on the ground floor and the maximum floor acceleration at the roof level. Aslani [13] however notes that the sufficiency of $S_{d e}$ with respect to $M_{w}$ will decrease as the influence of higher modes increases. This was illustrated by Luco and Cornell [7] who found $S_{d e}$ to be sufficient with respect to $M_{w}$ for a 9-storey structure, but insufficient for a 20-storey structure. Aslani [13] illustrated that an IM equivalent to $P G A$ was insufficient with respect to $M_{w}$ for predicting maximum interstorey drifts, but is sufficient with respect to $R$. $P G A$ was also found to be sufficient with respect to $M_{w}$ and $R$ for predicting maximum floor accelerations. Luco and Cornell [7] illustrate that $S_{d i}$ is sufficient with respect to both $M_{w}$ and $R$ when used for predicting peak interstorey drift ratio over all floors.

The majority of the above trends found by previous research were also observed for the seismic response analysis of the case study structure presented in this manuscript. Figure 7 illustrates the sufficiency of the five different IMs with respect to $M_{w}$ and $R$ when predicting peak interstorey drifts and peak floor accelerations. Similar to the variation in efficiency of the different IMs over the height of the structure, there is also variation in sufficiency of the IMs for different EDPs. For example, $S_{d i}$ is found to be less sufficient with respect to $M_{w}$ and $R$ in the upper floors of the structure, where higher mode effects are more prominent (as $S_{d i}$ cNum $>159</$ RecNum $><$ recor period-lengthening effects). Both $S_{d e}$ and $S_{d i}$ were found to be sufficient for predicting peak floor accelerations in the structure (having p-values less than 0.05 with respect to $R$ in Figure $7 \mathrm{~d}$ ), which is controlled by higher mode vibrations. $P G A$ is sufficient for both $M_{w}$, and $R$ at predicting peak floor accelerations but less sufficient at predicting peak interstorey drifts in the central half (i.e. storeys 2-7) of the structure which is dominated by the first-mode response. The velocity-based IMs ( $P G V$ and $S I)$ are generally found to be sufficient with respect to $M_{w}$ and $R$ for predicting peak interstorey drifts, and relatively sufficient at predicting peak floor accelerations (sufficient with respect to $M_{w}$, but 
marginally insufficient with respect to $R$ ). Thus it appears to be a clear trend that the better the efficiency of an IM at predicting a specific EDP, the better its sufficiency with respect to $M_{w}$ and $R$.

To explain the relationship between efficiency and sufficiency described above assume that EDP is a deterministic function of multiple explanatory variables; $E D P=f(\boldsymbol{\Theta})$. Uncertainty in the EDP for a given IM occurs because the IM does not account for all of the explanatory variables which influence EDP. Now if a particular IM correlates strongly with a large majority of the explanatory variables, $\boldsymbol{\Theta}$, then given IM the uncertainty in EDP will be relatively small (i.e. IM will be efficient at predicting EDP). Because of the strong correlation of IM and many of the explanatory variables, then the response conditioned on IM will already implicitly account for many of the other explanatory variables and hence EDP conditioned on IM will be (practically speaking) independent (i.e. sufficient) with respect to these explanatory variables.
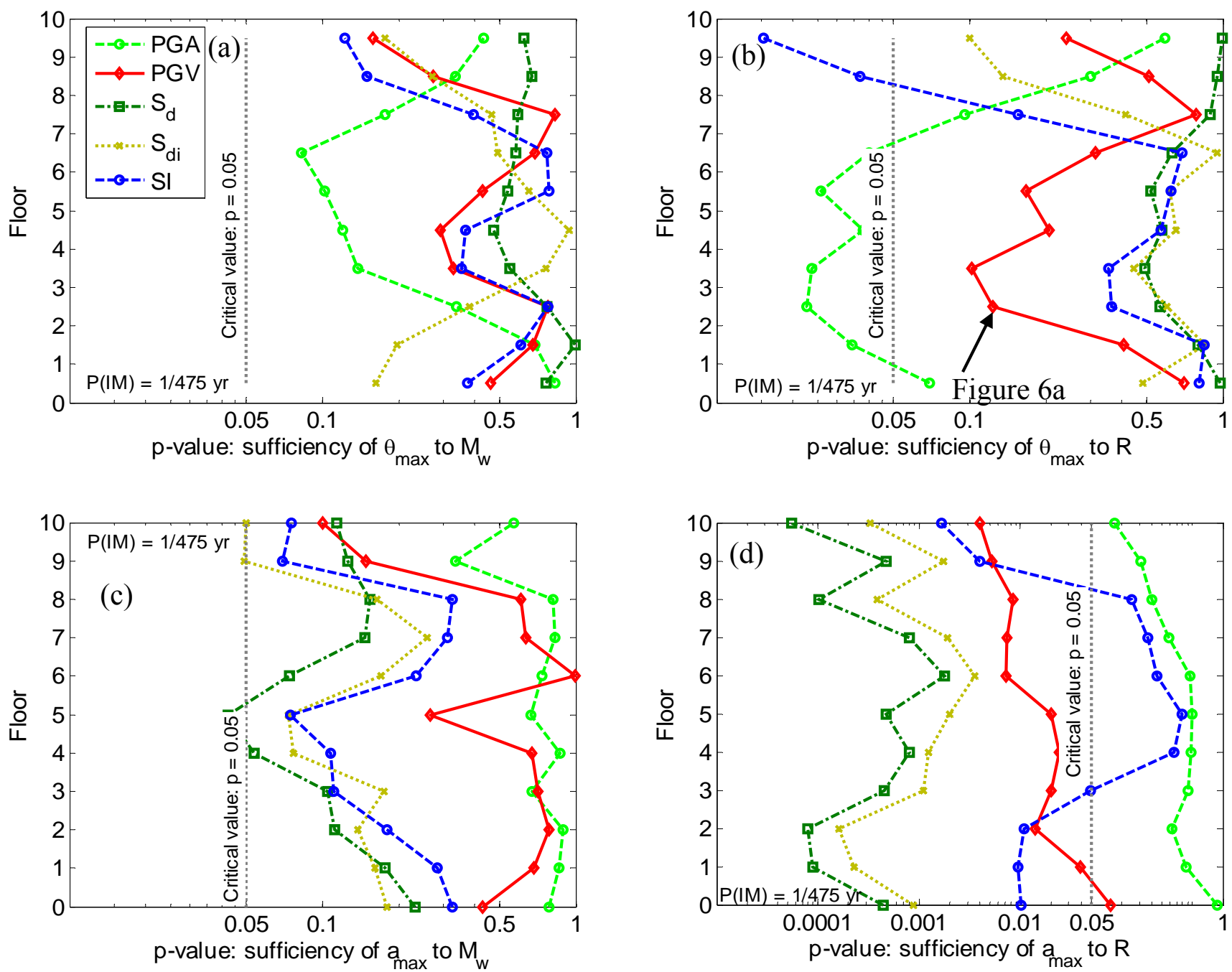

Figure 7: Sufficiency of the various IMs with respect to magnitude and distance when predicting peak interstorey drifts and peak floor accelerations

\section{Sufficiency with respect to 'epsilon'}

As previously noted, the parameter epsilon $(\varepsilon)$ is defined as the number of standard deviations a specific ground motion parameter is above the mean predicted by a ground 
motion prediction equation. Epsilon is one of three parameters which can be obtained from seismic hazard deaggregation (the other two being $M_{w}$ and $R$ ). In particular, because of the partial-correlated nature of spectral acceleration ordinates at different periods, Baker and Cornell [6] have shown that when ground motion records are scaled to a common $S_{a}(T)$ value (this includes $S_{d e}$ and $P G A$ of the IMs examined here), $\varepsilon$ can be used as a proxy for spectral shape, and therefore the extent to which higher-modes and period elongation will affect the seismic response for a given ground motion. Tothong and Luco [5] illustrate why $S_{d i}$ accounts for spectral shape at periods longer than that which the ground motions are scaled to (but not for spectral shape at higher mode periods). While Baker and Cornell [6] and Tothong and Luco [5] focus on the effect of epsilon when investigating peak interstorey drift ratios, the same logic can be directly applied to its effect on peak floor accelerations.

Figure 8a illustrates the sufficiency of the five IMs with respect to $\varepsilon$, when predicting peak interstorey drifts. Since when ground motion records are scaled to $P G A, \varepsilon$ (being an indicator of spectral shape) will directly relate to the magnitude of the response spectra at longer periods, then $P G A$ is insufficient with respect to $\varepsilon$ for predicting interstorey drifts (which are mostly dominated by first mode vibration). Similarly, $S_{d e}$ and $S_{d i}$ are insufficient with respect to $\varepsilon$ in predicting peak floor accelerations and peak interstorey drifts in upper floors which are dominated by higher mode vibration. $P G V$ and $S I$ are found to be sufficient to $\varepsilon$ for predicting peak interstorey drifts, but insufficient for peak floor accelerations, as illustrated in Figure 8b.
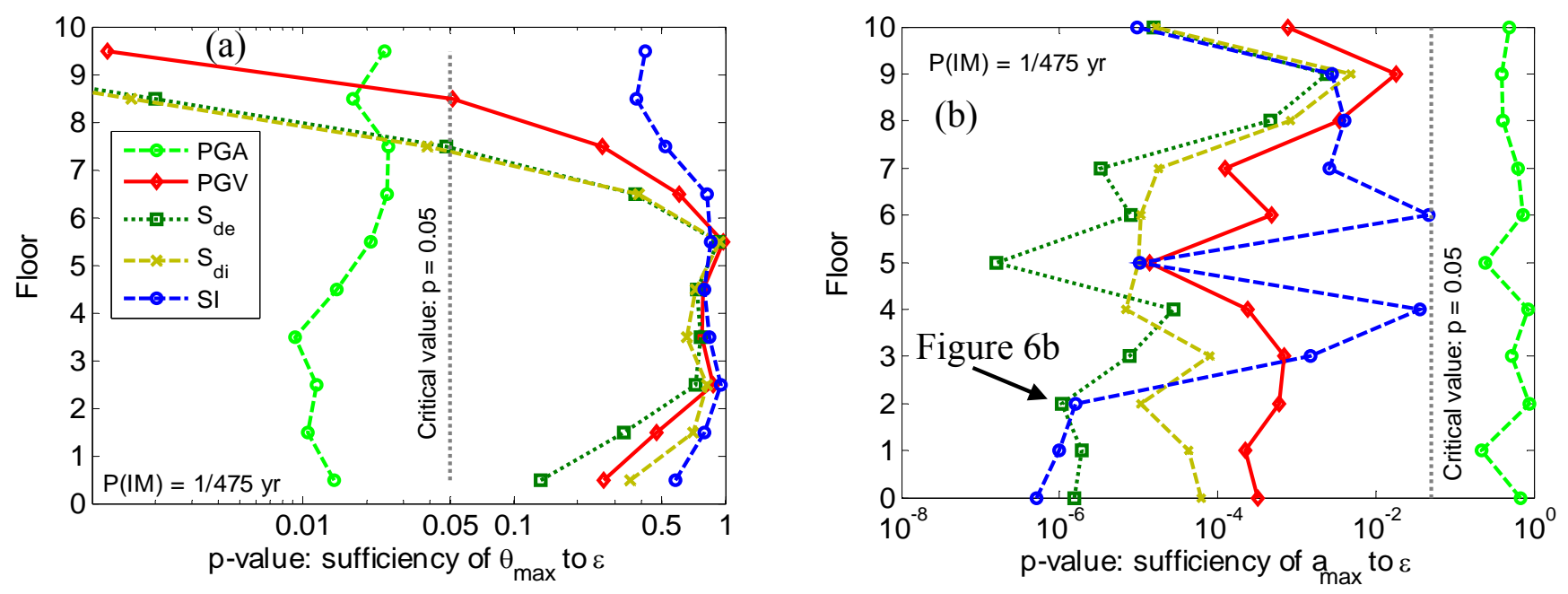

Figure 8: Sufficiency of the various IMs with respect to epsilon, $\varepsilon$

\section{Sufficiency with respect to scale factor (SF)}

The use of linear scaling (i.e. scaling amplitude without modifying frequency content or duration) ground motion records to a specific IM level has been scrutinized for introducing bias compared with some 'true' response that would be obtained using un-scaled ground motions. Luco and Bazzurro [11] have illustrated that when using $S_{d e}$ as an IM, scale factors that are significantly different from 1.0 can introduce significant bias in seismic response analysis. Baker [37] has shown however that careful ground motion selection (similar to what is used here) can significantly reduce such bias. Figure 9 illustrates the sufficiency of the five IMs with respect to SF for predicting peak interstorey drifts and peak floor accelerations. It can be seen that despite $P G A$ for peak interstorey drifts, and $P G V$ for peak floor accelerations, there is little dependence of the IMs on SF. As mentioned above this is likely the result of ground motion selection based on deaggregation of the seismic hazard. Also, because of the 
ground motion selection employed here, the scale factors required to scale the ground motions are not significantly large, with means of 2.1 and 3.2 (averaged over all five IMs) and ranges of 0.6-5.7 and 0.81-9.1 for the $1 / 475$ and $1 / 2475$ exceedance probabilities, respectively.
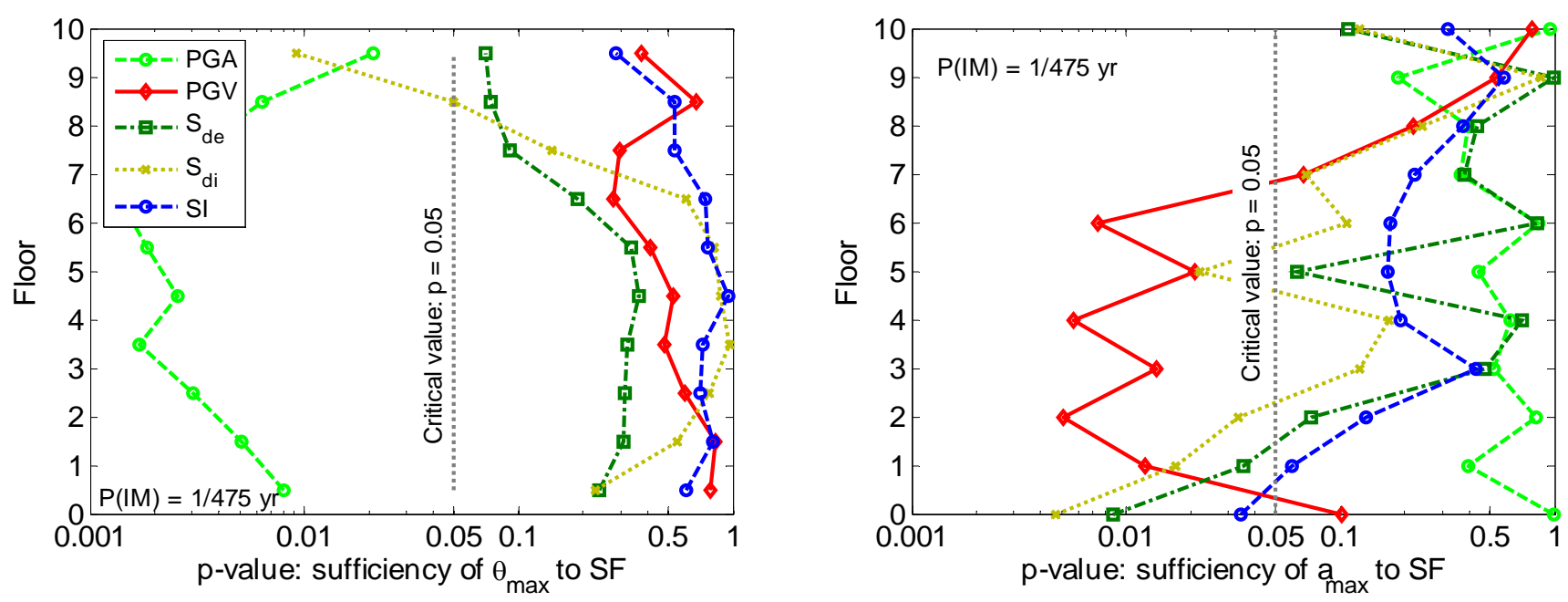

Figure 9: Sufficiency of the various IMs with respect to scale factor, SF

\section{Sufficiency with respect to site shear wave velocity, $V s_{30}$.}

With contemporary ground motion prediction equations [e.g., 20] giving soil site classification in terms of a $30-\mathrm{m}$ averaged shear wave velocity, $V s_{30}$, as opposed to a qualitative alphabet-based classification, it is possible to investigate the sufficiency of the various IMs with respect to $V s_{30}$. Figure 10 illustrates the sufficiency of the IMs investigated with respect to $V s_{30}$ for both peak interstorey drifts and peak floor accelerations. In general all IMs are sufficient with respect to $V_{S_{30}}$. It is also worth noting that the considered range $V s_{30}=300-800 \mathrm{~m} / \mathrm{s}$ represents relatively stiff soils. Further studies are needed to investigate the sufficiency with respect to $V s_{30}$ for soft soil deposits $\left(V s_{30}<300 \mathrm{~m} / \mathrm{s}\right)$ and significant nonlinearity in the soil response
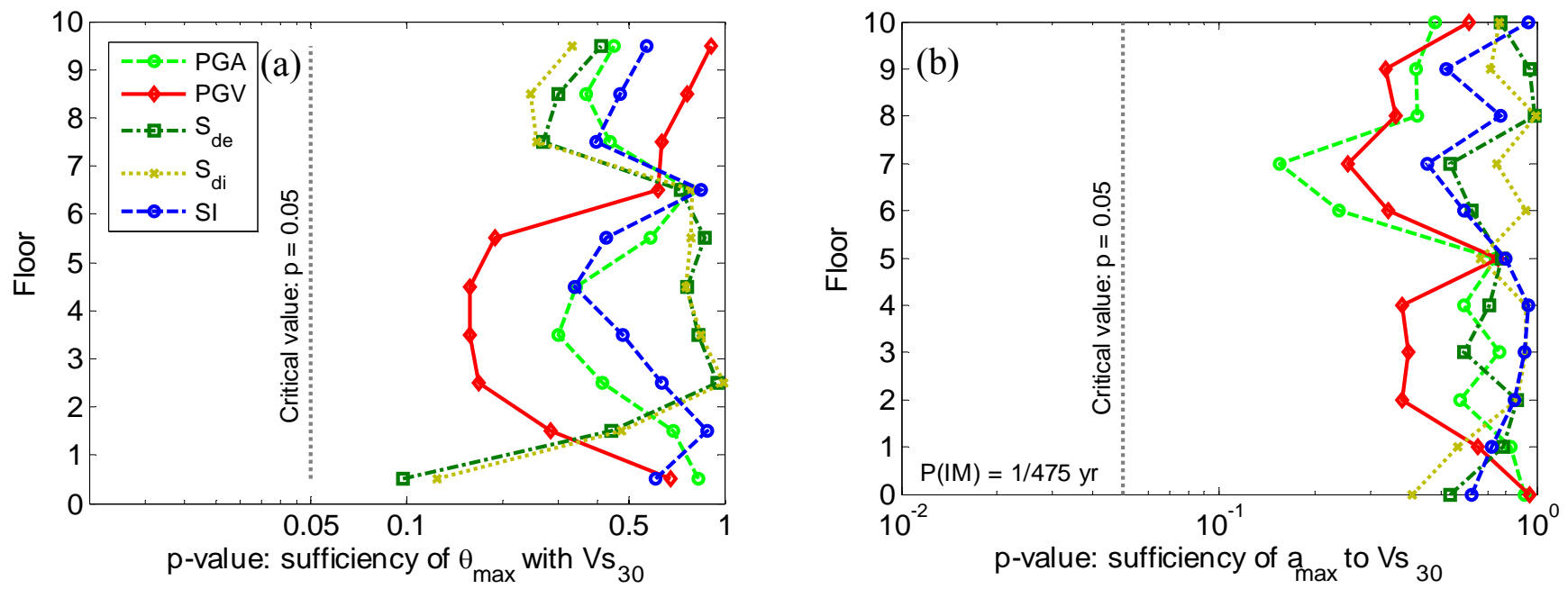

Figure 10: Sufficiency of the various IMs with respect to $30 \mathrm{~m}$-averaged site shear wave velocity, $\mathrm{Vs}_{30}$. 


\section{'Correcting' seismic demand distributions}

The aforementioned results have clearly illustrated that no single IM is sufficient with respect to $M_{w}, R, \varepsilon$, for all drift and floor acceleration demands in the case study structure. Therefore bias will be introduced in the computed response when the $\left(M_{w}, R, \varepsilon\right)$ distribution of the ground motion suite is different than that of the hazard deaggregation when predicting EDPs using an insufficient IM. It was also noted that it may be difficult to obtain a desired number of ground motion records which match the hazard deaggregation. In such cases, Bradley et al. [23] show that it is possible to regress on the results of the seismic response analyses to 'correct' the resulting distribution of EDP to reflect the $M_{w}, R, \varepsilon$ distribution from hazard deaggregation.

An alternative option is to avoid the "IM approach" and simply develop a prediction equation for the vector of EDPs directly as a function of ground motion parameters (e.g. magnitude, distance) (e.g. [38]). While this approach will not suffer from some of the problems of the IM approach discussed in this manuscript it should be made clear that the development of such a prediction equation for a vector of EDPs is complex, requiring significantly more seismic response analyses, complex regression analyses, expertise in strong ground motion modelling and access to ground motion metadata and earthquake fault databases. The IM approach bypasses these difficulties by separating seismic hazard analysis and seismic response analysis. Both approaches have their respective pros and cons and will thus be useful in different situations.

\section{CONCLUSIONS}

Prediction of the seismic response of multi-degree-of-freedom structures is a complex task due to the spatially distributed seismic demands which are sensitive to different frequency contents of the imposed ground motion. This manuscript investigated the efficacy of five different ground motion intensity measures (IMs): peak ground acceleration, $P G A$; peak ground velocity, $P G V$; elastic and inelastic spectral displacement, $S_{d e}$, $S_{d i}$; and spectrum intensity, $S I$, for which robust ground motion prediction equations are available. The concepts of predictability, efficiency, and sufficiency were investigated for each of the IMs when applied to the seismic response analysis of a 10-storey RC frame structure. It was illustrated that the efficiency (uncertainty in seismic response prediction) of an IM can be qualitatively determined based on the frequency range of the ground motion which controls the IM to that which controls the EDP being monitored. The predictability (uncertainty in ground motion prediction) of an IM was clearly shown to be an important factor in reducing the median response demand for ground motions scaled to an IM with a given probability of exceedance. Ground motion IMs which are predictable (namely $P G A, P G V$ and $S I$ ), result in lower median seismic demands when ground motions are scaled to a specific probability of exceedance using a seismic hazard curve. The sufficiency of the IM (the dependence of the seismic response on parameters such as $M_{w}, R$, and $\varepsilon$ ) was found to be closely related to the efficiency of the IM (the more efficient the IM, the higher the sufficiency), and it was observed that all IMs were insufficient with respect to at least one of $M_{w}, R$, or $\varepsilon$ when predicting both peak interstorey drifts and peak floor accelerations. As a result of the insufficiency of an IM, careful ground motion selection (compatible with the hazard deaggregation) and/or appropriate response modification is therefore needed to reduce bias and dispersion.

\section{ACKNOWLEDGEMENTS}

Financial support of the first author from the New Zealand Tertiary Education Commission Bright Futures scheme is appreciated. 


\section{REFERENCES:}

[1] Cornell CA and Krawinkler H. Progress and challenges in seismic performance assessment. PEER Center News 2000; 3(2).

[2] Shome N and Cornell CA. Probabilistic seismic demand analysis of nonlinear structures. Report No. RMS-35, RMS Program,Stanford University, Stanford, CA, 1999. 357. http://www.stanford.edu/group/rms/

[3] Luco N. Probablistic Seismic Demand Analysis, Connection Fractures, and Near-Source Effects. Ph.D. Thesis, Department of Civil and Environmental Engineering Stanford University, 2002, 285.

[4] Kramer SL and Mitchell RA. Ground motion intensity measures for liquefaction hazard evaluation. Earthquake Spectra 2006; 22(2): 413-438.

[5] Tothong P and Luco N. Probabilistic Seismic Demand Analysis Using Advanced Ground Motion Intensity Measures. Earthquake Engineering and Structural Dynamics 2007; 36(13): 1837-1860.

[6] Baker JW and Cornell CA. A vector-valued ground motion intensity measure consisting of spectral acceleration and eplison. Earthquake Engineering and Structural Dynamics 2005; 34(10): 1193-1217.

[7] Luco N and Cornell CA. Structure-specific scalar intensity measures for near-source and ordinary earthquake ground motions. Earthquake Spectra 2007; 23(2): 357-392, DOI: $10.1193 / 1.2723158$.

[8] Shome N, Cornell CA, Bazzurro P, and Carballo JE. Earthquakes, records, and nonlinear responses. Earthquake Spectra 1998; 14(3): 469-500.

[9] Vamvatsikos D and Cornell CA. Developing efficient scalar and vector intensity measures for IDA capacity estimation by incorporating elastic spectral shape information. Earthquake Engineering and Structural Dynamics 2005; 34(13): 1573-1600.

[10] Baker JW and Cornell CA. Spectral Shape, record selection and epsilon. Earthquake Engineering and Structural Dynamics 2006; 35(9): 1077-1095.

[11] Luco N and Bazzurro P. Does amplitude scaling of ground motion records result in biased nonlinear structural drift responses? Earthquake Engineering and Structural Dynamics 2007; 36(13): 1813-1835, DOI: 10.1002/eqe.695.

[12] Taghavi S and Miranda E. Probabilistic study of peak floor acceleration demands in linear structures, in 9th International Conference on Applications of Statistics and Probability in Civil Engineering, San Francisco, CA, 2003, 8.

[13] Aslani H. Probabilistic earthquake loss estimation and loss disaggregation in buildings. Ph.D. Thesis, John A. Blume Earthquake Engineering Centre, Dept. of Civil and Environmental Engineering Stanford University, 2005, 382.

[14] Bradley BA, Dhakal RP, Cubrinovski M, and MacRae GA. Prediction of Spatially Distributed Seismic Demands in Structures: From Structural Response to Loss Estimation. Earthquake Engineering and Structural Dynamics 2008: (submitted).

[15] Bull DK and Brunsdon D. Examples of Concrete Structural Design to New Zealand Standards 3101. New Zealand, 1998.

[16] Standards New Zealand. NZS 3101 1995: Part 1: Concrete Structures Standard. Wellington, NZ, 1995.

[17] McKenna F, Fenves GL, and Scott MH. OpenSees: Open System for Earthquake Engineering Simulation.: Pacific Earthquake Engineering Research Center, University of California, Berkeley, CA, 2004.

[18] Kramer SL. Geotechnical Earthquake Engineering. Prentice-Hall: Upper Saddle River, NJ., 1996; 653.

[19] Peng B, Dhakal R, Fenwick R, Carr A, and Bull D. Experimental investigation on the interaction of reinforced concrete frames with precast-prestressed concrete floor systems. 14th 
World Conference on Earthquake Engineering, Beijing, China, 2008.

[20] Power M, Chiou B, Abrahamson NA, Bozorgnia Y, Shantz T, and Roblee C. An Overview of the NGA Project. Earthquake Spectra 2008; 24(1): 3-21.

[21] Tothong P and Cornell CA. An Emperical Ground Motion Attenuation Equation for Inelastic Spectral Displacement. Bulletin of the Seismological Society of America 2006; 96(6): 2146-2164.

[22] Housner GW. Spectrum intensities of strong-motion earthquakes, in Symposium on earthquakes and blast effects on structures, Los Angeles, CA, 1952.

[23] Bradley BA, Cubrinovski M, MacRae GA, and Dhakal RP. Ground motion prediction equation for Spectum intensity from spectral acceleration relationships. Bulletin of the Seismological Society of America (in press) 2008.

[24] Boore DM and Atkinson GM. Ground-motion prediction equations for the average horizontal component of PGA, PGV, and 5\%-damped PSA at spectral periods between $0.01 \mathrm{~s}$ and 10.0s. Earthquake Spectra 2008; 24(1): 99-138.

[25] Field EH, Jordan TH, and Cornell CA. OpenSHA: A Developing Community-Modelling Environment for Seismic Hazard Analysis. Seismological Research Letters 2003; 74: 406419.

[26] Boore DM, Watson-Lamprey J, and Abrahamson NA. Orientation-Independent Measures of Ground Motion. Bulletin of the Seismological Society of America 2006; 96(4A): 15021511, DOI: 10.1785/0120050209.

[27] Goulet CA, Watson-Lamprey J, Baker JW, Haselton CB, and Luco N. Assessment of Ground Motion Selection and Modification (GMSM) methods for non-linear dynamic analyses of structures. Geotechnical Earthquake Engineering and Soil Dynamics IV (GSP 181), Sacramento, CA, 2008.

[28] McGuire RK. Probabilistic seismic hazard analysis and design earthquakes: closing the loop. Bulletin of the Seismological Society of America 1995; 85(5): 1275-1284.

[29] Bazzurro P and Cornell CA. Disaggregation of seismic hazard. Bulletin of the Seismological Society of America 1999; 89(2): 501-520.

[30] Chiou B, Darragh R, Gregor N, and Silva WJ. NGA Project Strong-Motion Database. Earthquake Spectra 2008; 24(1): 23-44.

[31] Baker JW and Cornell CA. Which Spectral Acceleration Are You Ysing? Earthquake Spectra 2006; 22(2): 293-312.

[32] Bommer JJ and Abrahamson NA. Why Do Modern Probabilistic Seismic-Hazard Analyses Often Lead to Increased Hazard Estimates? Bulletin of the Seismological Society of America 2006; 96(6): 1967-1977, DOI: 10.1785/0120060043.

[33] McGuire RK. Seismic Hazard and Risk Analysis. Earthquake Engineering Research Institute, 2004; 221.

[34] Beyer K and Bommer JJ. Selection and Scaling of Real Accelerograms for Bi-Directional Loading: A Review of Current Practice and Code Provisions. Journal of Earthquake Engineering 2007; 11(1): 13-45, DOI: 10.1080/13632460701280013.

[35] Aslani H and Miranda E. Probability-based Seismic Response Analysis. Engineering Structures 2005; 27(8): 1151-1163.

[36] Ang AHS and Tang WH. Probability Concepts in Engineering Planning and Design vol. Volume I - Basic Principles. John Wiley \& Sons, Inc., 1975; 406.

[37] Baker JW. Measuring Bias in Structural Response Caused by Ground Motion Scaling, in 8th Pacific Conference on Earthquake Engineering, Singapore, 2007, 8.

[38] Hancock J, Bommer JJ, and Stafford PJ. Numbers of scaled and matched accelerograms required for inelastic dynamic analyses. Earthquake Engineering and Structural Dynamics 2008; 37(14): 1585-1702, DOI: 10.1002/eqe.827. 